\title{
Efficacy of duodenal bulb biopsy for diagnosis of celiac disease: a systematic review and meta-analysis
}

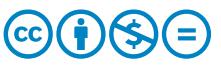

\author{
Authors \\ Institutions \\ 1 Department of Internal Medicine, Yale University School \\ of Medicine, New Haven, Connecticut, United States \\ 2 Division of Gastroenterology and Hepatology, University \\ of New Mexico, Albuquerque, New Mexico, United \\ States
}

Thomas R. McCarty ${ }^{1}$, Corey R. O'Brien ${ }^{1}$, Anas Gremida ${ }^{2}$, Christina Ling ${ }^{2}$, Tarun Rustagi ${ }^{2}$

submitted 7.5.2018

accepted after revision 23.7.2018

Bibliography

DOI https://doi.org/10.1055/a-0732-5060 |

Endoscopy International Open 2018; 06: E1369-E1378

(c) Georg Thieme Verlag KG Stuttgart · New York ISSN 2364-3722

Corresponding author

Tarun Rustagi, MD, Division of Gastroenterology and Hepatology, University of New Mexico, MSC10 5550, 1 University of New Mexico, Albuquerque NM 87131

Fax: +1-505-272-9751

tarunrustagi06@gmail.com

\section{ABSTRACT}

Background and study aims Although duodenal biopsy is considered the "gold standard" for diagnosis of celiac disease, the optimal location of biopsy within the small bowel for diagnosis remains unclear. The primary aim of this study was to perform a structured systematic review and meta-a- nalysis to evaluate the diagnostic utility of endoscopic duodenal bulb biopsy for celiac disease.

Patients and methods Searches of PubMed, EMBASE, Web of Science, and Cochrane Library databases were performed from 2000 through December 2017. Review of titles/abstracts, full review of potentially relevant studies, and data abstraction was performed. Measured outcomes of adult and pediatric patients included location of biopsy, mean number of biopsies performed, and diagnosis of celiac disease as defined by the modified Marsh-Oberhuber classification.

Results A total of 17 studies $(n=4050)$ were included. Seven studies evaluated adults and 11 studies assessed pediatric populations. Mean age of adults and pediatric patients was $46.70 \pm 2.69$ and $6.33 \pm 1.26$ years, respectively. Overall, sampling from the duodenal bulb demonstrated a $5 \%$ (95\% Cl 3-9; $P<0.001)$ increase in the diagnostic yield of celiac disease. When stratified by pediatric and adult populations, duodenal bulb biopsy demonstrated a $4 \%(95 \% \mathrm{Cl}$ : 1 to $9 ; P<0.001)$ and $8 \%(95 \% \mathrm{Cl}: 6$ to $10 ; P<0.001)$ increase in the diagnostic yield of celiac disease. Non-celiac histologic diagnoses including Brunner gland hyperplasia and peptic duodenitis were reported more commonly in the duodenal bulb as compared to the distal duodenum with an increase in diagnostic yield of $4 \%(95 \% \mathrm{Cl} 3-5 ; P<$ $0.001)$ and $1 \%(95 \% \mathrm{Cl} 1-2 ; P<0.001)$, respectively.

Conclusions Based upon our results, biopsy and histologic examination of duodenal bulb during routine upper endoscopy increases the diagnostic yield of celiac disease.

\section{Introduction}

Celiac disease is an immune-mediated gluten-dependent enteropathy that affects the small bowel [1]. While reports of prevalence vary, celiac disease is estimated to affect $0.5 \%$ to $1 \%$ of the United States population [2-4]. Gluten is a ubiquitous protein present in foods like wheat, barley, and rye $[1,5]$ Celiac disease, often called gluten-sensitive enteropathy, can result in symptomatic malabsorption and may present with a breadth of symptoms including diarrhea, bloating, and fatigue. If untreated, celiac disease may lead to iron deficiency anemia, vitamin D deficiency, vitamin B12 deficiency, and intestinal lymphoma, thus signifying a need to ensure an accurate diagnosis $[1,6]$.

Despite the need to ensure appropriate identification, diagnosis of celiac disease is often challenging and delayed as there is a considerable overlap between celiac disease and other gastroenterological disorders such as irritable bowel syndrome [7]. Diagnosis includes serologic testing, typically via tissue transglutaminase antibody (TTG- $\lg A)$, with or without the use of duodenal biopsy. Duodenal biopsy is generally performed if serologic testing is positive, if there is a high pre-test probability 
for celiac disease, or if there are discordant results of serologic testing [7]. Pathologic diagnosis is established or confirmed according to the modified Marsh-Oberhuber classification, which accounts for the number of intraepithelial lymphocytes, crypt hyperplasia, and villous atrophy $[8,9]$.

As celiac disease may result in patchy histologic changes in the small bowel, the site and number of duodenal biopsies becomes of considerable importance. Biopsies were classically obtained from the distal duodenum (i. e., sections duodenal stage 2 [D2] through D4). However, there have been an increasing number of studies that have evaluated biopsy of the duodenal bulb (i. e., section D1) for diagnosis of celiac disease in the adult and pediatric populations [7,10-12]. When compared to distal duodenal biopsies alone, duodenal bulb biopsies may increase the diagnostic yield; however, studies to date have shown varied results.

The primary aim of this study was to perform a systematic review and meta-analysis to evaluate the feasibility, efficacy, and tolerability of duodenal bulb biopsy for the diagnosis of celiac disease in the adult and pediatric populations. We hypothesized that duodenal bulb biopsy would improve the diagnostic yield of celiac disease as compared to distal duodenal sampling alone.

\section{Methods}

\section{Literature search}

A comprehensive search of the literature was performed to identify articles that examined endoscopic duodenal biopsy for the diagnosis of celiac disease. We followed previously cited recommendations for search strategies to identify diagnostic accuracy studies [13]. Systematic searches of PubMed, EMBASE, Web of Science, and the Cochrane Library databases were performed from 2001 through December 31, 2017. The search terms included: "endoscopic duodenal biopsy", "celiac disease", "gluten-sensitive enteropathy”, “celiac sprue”, "nontropical sprue”, "endemic sprue”, and “duodenal bulb”.

All relevant articles irrespective of language, year of publication, type of publication, or publication status were included. The titles and abstracts of all potentially relevant studies were screened for eligibility. The reference lists of studies of interest were then manually reviewed for additional articles by cross checking bibliographies. Two reviewers (TRM and CRO) independently screened the titles and abstracts of all the articles according to predefined inclusion and exclusion criteria. Any differences were resolved by mutual agreement and in consultation with the third reviewer (TR). In the case of studies with incomplete information, contact was attempted with the principal authors to obtain additional data.

\section{Study selection criteria}

Only studies investigating use of endoscopic biopsy for the diagnosis of celiac disease were included. Only human subject studies were considered in the analysis. A study was excluded if deemed to have insufficient data, as were review articles, editorials, and correspondence letters that did not report independent data. Case series and reported studies with fewer than five patients were excluded. Participants included patients of any age in whom the presence of celiac disease was suspected based upon clinical symptoms alone or positive serologic markers were included. The Preferred Reporting Items for Systematic Reviews and Meta-Analyses (PRISMA) statement outline for reporting systematic reviews and meta-analyses was used to report findings [14].

\section{Outcome measures}

The primary outcome measurement in this study was efficacy of endoscopic duodenal bulb biopsy in patients with suspected celiac disease. Location of biopsy within the duodenum was defined as duodenal bulb (i. e., section D1) versus distal duodenal (i. e., sections D2 through D4). Secondary measured outcomes in addition to location of biopsy included mean number of biopsies performed, confirmatory diagnosis of celiac disease as defined by the modified Marsh-Oberhuber classification, and type and number of alternative diagnoses potentially identified (i. e., Brunner gland hyperplasia, peptic duodenitis, gastric metaplasia, or other). Information on type and year of study, average patient age (years), and gender were also collected. Sensitivity and subgroup analyses were also performed for only highquality studies (i.e., inclusion of only randomized controlled trials or prospective studies), diagnostic yield as stratified by pediatric and adult populations, and number of small bowel biopsies.

\section{Statistical analysis}

This meta-analysis was performed by calculating pooled proportions. After appropriate studies were identified through systematic review, the individual study proportion was transformed into a quantity using the Freeman-Tukey variant of the arcsine square root transformed proportion. Then the pooled proportion was calculated as the back transform of the weighted mean of the transformed proportions, using inverse arcsine variance weights for the fixed effects model and DerSimonianLaird weights for the random effects model $[15,16]$.

Measured outcomes comparing site of duodenal biopsy were obtained. From this, standardized mean difference was calculated and transformed to the natural logarithm before pooling, and the variance was calculated. Fixed-effects models were applied to duodenal bulb and distal duodenal biopsy data to determine effect size and corresponding 95\% confidence intervals (Cls). Since this was a cumulative meta-analysis, publication bias was not assessed. Combined weighted proportions, and meta-regression were determined by use of the Stata 13.0 software package (Stata Corp LP, College Station, TX).

\section{Results}

\section{Patient characteristics of included studies}

This meta-analysis included a total of 17 studies [10-12,1730]. A PRISMA flow chart of search results is shown in $>$ Fig. 1. A total of 4050 patients (males $n=1707 ; 42.15 \%$ ) were included in this study. Mean age of all patients included was $35.07 \pm$ 20.66 years. Both adult and pediatric populations were included in this study as well. Adult patients made up the vast major- 


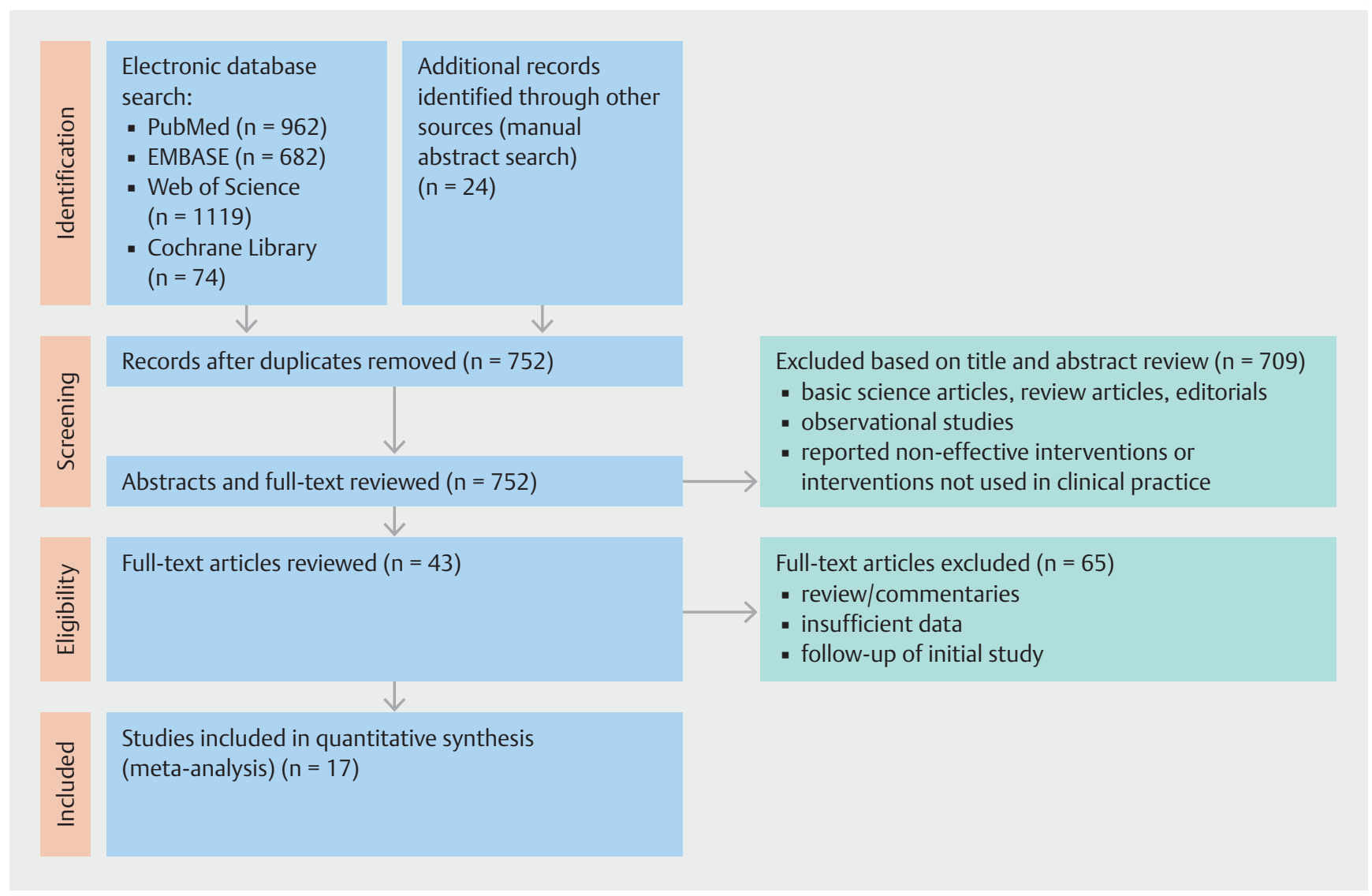

- Fig. 1 Preferred reporting items for systematic reviews and meta-analyses (PRISMA) flow chart of search results for duodenal bulb biopsy.

ity ( $\mathrm{n}=2684 ; 66.27 \%$ ) of enrolled patients in this systematic review and meta-analysis. Mean age of adults and pediatric patients was $46.70 \pm 2.69$ and $6.33 \pm 1.26$ years, respectively. All but two studies commented on the number of bulb biopsies performed; however, many included "at least one" or "at least two" and other studies ranged from one to five samples taken. Fourteen prospective and three retrospective studies were included. All three retrospective studies examined pediatric populations $[18,21,22]$. No randomized controlled trials were found and included in this systematic review and meta-analysis. Further baseline patient and study characteristics are highlighted in $>$ Table 1.

\section{Duodenal biopsy findings}

Of the total patients included in this systematic review and meta-analysis, $47.46 \%(n=1922)$ were diagnosed with celiac disease based upon a positive biopsy result from any location in the duodenum. Fourteen studies found biopsy of the duodenal bulb to increase the diagnostic yield of celiac disease [10 $12,17-20,22-25,27,29,30$ ] A total of three included studies demonstrated no improvement in diagnostic accuracy of celiac disease with duodenal bulb biopsy $[21,26,28]$.

Overall, the diagnosis of celiac disease was histologically confirmed in $97 \%$ (95\% Cl: 91 to 100; $P<0.001)$ of biopsy samples obtained from the duodenal bulb ( $\vee$ Fig. 2). From the distal duodenum, histologic confirmation of celiac disease was re- ported in $89 \%(95 \% \mathrm{Cl}: 81$ to $94 ; P<0.001)$ of biopsy samples ( $\triangleright$ Fig.3) The sampling for the duodenal bulb demonstrated an overall increase of $5 \%(95 \% \mathrm{Cl}: 3$ to $9 ; P<0.001)$ in the diagnostic yield of celiac disease ( $\mathbf{F i g} .4)$. Non-celiac histologic diagnoses including Brunner gland hyperplasia and peptic duodenitis were reported more commonly in the duodenal bulb as compared to the distal duodenum with an increase in diagnostic yield of $4 \%(95 \% \mathrm{Cl}: 3$ to $5 ; P<0.001)$ and $1 \%(95 \% \mathrm{Cl}: 1$ to 2 ; $P<0.001$ ) ( $\triangleright$ Supplemental Fig. 1 and $\triangleright$ Supplemental Fig. 2).

\section{Sensitivity and subgroup analyses}

Sensitivity analysis including only high-quality manuscripts (i. e., prospective studies) demonstrated a similar increased diagnostic yield of duodenal bulb biopsy as compared to our cumulative meta-analysis results, $5 \%(95 \% \mathrm{Cl}: 3$ to $8 ; P<0.001)$ ( Supplemental Fig. 3). When stratified by pediatric and adult populations, duodenal bulb biopsy demonstrated a $4 \%(95 \% \mathrm{Cl}$ : 1 to 9$)$ and $8 \%(95 \% \mathrm{Cl}: 6$ to 10$)$ increase in the diagnostic yield of celiac disease, respectively $(P<0.001)$ ( $\$$ Supplemental Fig. 4 and $\triangleright$ Supplemental Fig. 5). Further breakdown of our results by number of biopsies revealed that two studies performed less than the recommended number of biopsies from the distal duodenum $[12,26]$. When these studies were excluded, biopsy of the duodenal bulb increased the diagnostic yield of celiac disease by $6 \%(95 \% \mathrm{Cl}: 3$ to $10 ; P<0.001)$ ( Supplemental Fig. 6). More biopsies of the duodenal bulb (i.e., $>2$ 
- Table 1 Characteristics of included studies to assess duodenal bulb biopsy for celiac disease.

\begin{tabular}{|c|c|c|c|c|c|c|c|c|}
\hline Author & Year & $\begin{array}{l}\text { Study } \\
\text { design }\end{array}$ & $\begin{array}{l}\text { Number } \\
\text { of pa- } \\
\text { tients }\end{array}$ & $\begin{array}{l}\text { Mean } \\
\text { age } \\
\text { (years) }\end{array}$ & $\begin{array}{l}\text { Number } \\
\text { of males }\end{array}$ & $\begin{array}{l}\text { Minimum number of } \\
\text { bulb biopsies }\end{array}$ & $\begin{array}{l}\text { Distal } \\
\text { confir- } \\
\text { mation }\end{array}$ & $\begin{array}{l}\text { Bulb } \\
\text { confir- } \\
\text { mation }\end{array}$ \\
\hline \multicolumn{9}{|l|}{ Adult study population } \\
\hline Stoven et al. & 2016 & Prospective & 679 & 50 & 324 & Bulb $(n=2)$; Distal $(n=4)$ & $17 / 18$ & $18 / 18$ \\
\hline Mooney et al. & 2016 & Prospective & 1378 & 50.3 & 661 & Bulb $(n=4)$; Distal $(n=4)$ & $242 / 268$ & $268 / 268$ \\
\hline Caruso et al. & 2013 & Prospective & 55 & 35.67 & 11 & Bulb $(n=4)$; Distal $(n=4)$ & $25 / 38$ & $27 / 38$ \\
\hline Kurien et al. & 2012 & Prospective & 28 & 48 & 9 & Bulb $(n=4)$; Distal $(n=4)$ & $23 / 28$ & $26 / 28$ \\
\hline Nenna et al. & 2012 & Prospective & 43 & 35.2 & 10 & Bulb $(n=2)$; Distal $(n=3)$ & $42 / 43$ & $43 / 43$ \\
\hline Evans et al. & 2011 & Prospective & 461 & 51 & 161 & Bulb $(n=1)$; Distal $(n=4)$ & $132 / 211$ & $148 / 211$ \\
\hline Gonzalez et al. & 2010 & Prospective & 40 & 45 & 30 & Bulb $(n=2)$; Distal $(n=4)$ & $35 / 40$ & $40 / 40$ \\
\hline \multicolumn{9}{|c|}{ Pediatric study population } \\
\hline Mansfield-Smith et al. & 2014 & Retrospective & 60 & 8.42 & 19 & - & $42 / 60$ & $54 / 60$ \\
\hline Sharma et al. & 2013 & Retrospective & 101 & 8.21 & 33 & Bulb $(n=1)$; Distal $(n=4)$ & $93 / 101$ & $99 / 101$ \\
\hline Tanpowpong et al. & 2012 & Retrospective & 103 & 8.5 & 40 & - & $83 / 103$ & $79 / 103$ \\
\hline Levinson-Castiel et al. & 2011 & Prospective & 96 & 6 & 31 & Bulb $(n=1)$; Distal $(n=4)$ & $81 / 87$ & $86 / 87$ \\
\hline Mangiavillano et al. & 2010 & Prospective & 47 & 8.1 & 14 & Bulb $(n=4)$; Distal $(n=4)$ & $42 / 47$ & $47 / 47$ \\
\hline Rashid et al. & 2009 & Prospective & 35 & 8.1 & 14 & Bulb $(n=2)$; Distal $(n=4)$ & $31 / 35$ & $33 / 35$ \\
\hline Prasad et al. & 2009 & Prospective & 52 & 6.4 & 33 & Bulb $(n=2)$; Distal $(n=2)$ & $52 / 52$ & $52 / 52$ \\
\hline Bonamico et al. & 2008 & Prospective & 665 & 5.25 & 237 & Bulb $(n=1)$; Distal $(n=4)$ & $649 / 665$ & $665 / 665$ \\
\hline Ravelli et al. & 2005 & Prospective & 112 & 6.4 & 43 & Bulb $(n=4)$; Distal $(n=4)$ & $110 / 110$ & $110 / 110$ \\
\hline Bonamico et al. & 2004 & Prospective & 95 & 6.9 & 37 & Bulb $(n=1)$; Distal $(n=4)$ & $11 / 16$ & $16 / 16$ \\
\hline
\end{tabular}

bulb biopsies) did not significantly improve diagnostic yield of celiac disease as compared to overall results - increase yield of $6 \%$ (95\% Cl: 1 to $14 ; P<0.001)$ versus $5 \%(95 \% \mathrm{Cl}: 3$ to $9 ; P<$ $0.001)$, respectively.

\section{Discussion}

Based upon results from our systematic review and meta-analysis, biopsy and histologic examination of duodenal bulb during routine upper endoscopy appears to increase diagnostic yield and aid in the diagnosis of celiac disease. Among all patients, duodenal bulb biopsy improved diagnostic yield of celiac disease by $5 \%$. This is concordant with results identified in other trials $[19,24,25]$. Even when stratified by pediatric and adult populations, endoscopic bulb biopsy was shown to be an effective strategy to improve diagnostic accuracy. Importantly, this general practice of duodenal bulb sampling appears to increase diagnostic yield for both adult and pediatric patients. Therefore, gastroenterologists and endoscopists should consider sampling the duodenal bulb, in addition to the distal duodenum, to improve histologic diagnosis of celiac disease.

Celiac disease is an autoimmune enteropathy elicited by ingestion of gluten [31]. While the disease was traditionally thought to affect individuals of Northern European ancestry, celiac disease has now become increasingly recognized and reported in people of various racial/ethnic and geographical distributions including Asian andAfrican as well [32]. Within the last five decades, prevalence of celiac disease has increased five-fold affecting approximately $1 \%$ of individuals in many populations [33]. This global increase in prevalence reflects a true increase in incidence and has been shown to not be a result of increased awareness or screening efforts [31] However, even with a rising prevalence, evidence has suggested that the ratio of knownto unknown diagnosed celiac disease patients was one in seven, signifying that a substantial number of individuals may be unaware of their disease [34].

Current American College of Gastroenterology (ACG) guidelines recommend small bowel biopsy to confirm the diagnosis of celiac disease in patients with a positive serology and in those with a high probability of celiac disease (i.e., typically considered $\geq 5 \%$ ), regardless of the serology [7]. Supported by a high level of evidence, the ACG also highlights upper endoscopy with small-bowel biopsy as a critical component of the diagnostic evaluation for persons with suspected celiac disease and to confirm the diagnosis suggesting multiple biopsies be obtained from the duodenum with one or two from the bulb 


\section{Study}

Bonamico et al. (2004)

Ravelli et al. (2005)

Bonamico et al. (2008)

Prasad et al. (2009)

Rashid et al. (2009)

Gonzalez et al. (2010)

Mangiavillano et al. (2010)

Evans et al. (2011)

Levinson-Castiel et al. (2011)

Kurien et al. (2012)

Nenna et al. (2012)

Tanpowpong et al. (2012)

Caruso et al. (2013)

Sharma et al. (2013)

Mansfield-Smith et al. (2014)

Mooney et al. (2016)

Stoven et al. (2016)

Overall $\left(I^{2}=94.97 \%, P=0.00\right)$

.1.2.3.4.5.6.7.8.91

Proportion

- Fig. 2 Overall diagnostic accuracy of duodenal bulb biopsy for diagnosis of celiac disease

\section{Study}

Bonamico et al. (2004)

Ravelli et al. (2005)

Bonamico et al. (2008)

Prasad et al. (2009)

Rashid et al. (2009)

Gonzalez et al. (2010)

Mangiavillano et al. (2010)

Evans et al. (2011)

Levinson-Castiel et al. (2011)

Kurien et al. (2012)

Nenna et al. (2012)

Tanpowpong et al. (2012)

Caruso et al. (2013)

Sharma et al. (2013)

Mansfield-Smith et al. (2014)

Mooney et al. (2016)

Stoven et al. (2016)

Overall $\left(I^{2}=93.90 \%, P=0.00\right)$

1.2.3.4.5.6.7.8.91

Proportion

- Fig. 3 Overall diagnostic accuracy of distal duodenal biopsy for the diagnosis of celiac disease.

\section{Study}

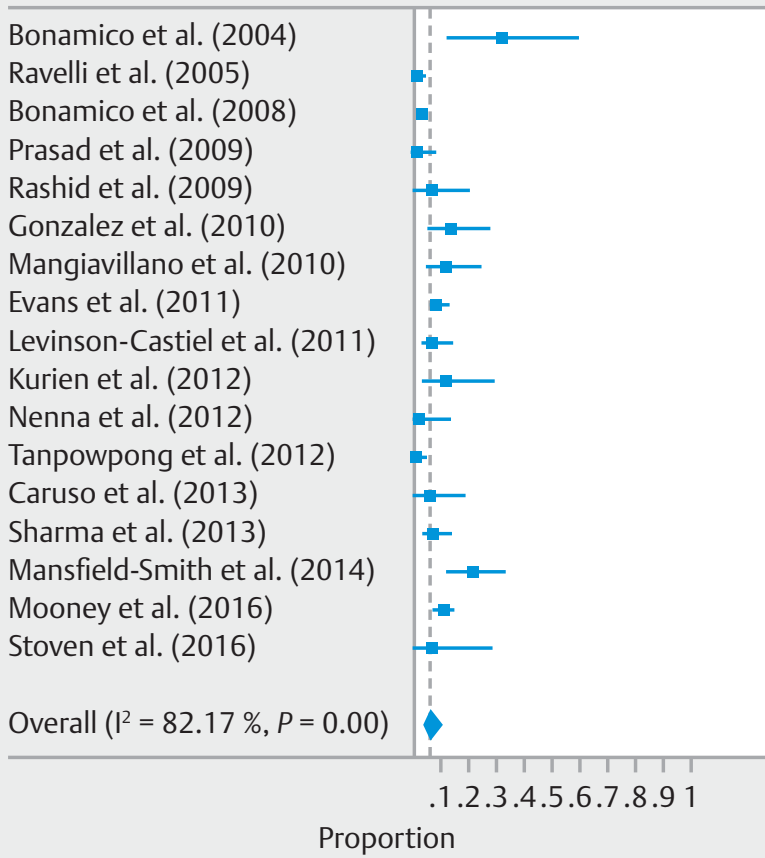

- Fig. 4 Overall diagnostic yield increase of duodenal bulb biopsy versus distal duodenal biopsy for the diagnosis of celiac disease.

at least four biopsies from the distal duodenum. Additional international and national pediatric and adult guidelines echo this statement but do not provide specific sites of the small intestine to sample [35-38] Classically, histologic features of celiac disease may range from mild alterations characterized by increased intraepithelial lymphocytes to a flat mucosa with villous atrophy, enhanced epithelial apoptosis, and crypt hyperplasia [39-44]. For this reason, small-intestinal biopsy has been central to confirmation of the diagnosis of celiac disease since the 1950s [45].

Despite this general statement regarding a role for biopsy in diagnosis of celiac disease, in the last decade there has been debate regarding the optimal biopsy sampling strategy with regards to location and number of biopsies. Current ACG guidelines recommend multiple biopsies of the duodenum (one or two biopsies of the bulb and at least four biopsies from the distal duodenum) to confirm the diagnosis of celiac diseasestrong recommendation, high level of evidence [7]. All studies included with the exception of two trials specifically followed these recommendations when evaluating the role for duodenal bulb biopsy and celiac disease diagnosis [12,26]. Importantly, more than two biopsies from the duodenal bulb did not appear to increase the diagnostic yield of celiac disease, suggesting that providers need not over-sample the bulb. These results reaffirm and strengthen the current ACG guidelines.

Despite our results questioning the utility of more than two duodenal bulb biopsies and possibly suggesting duodenal bulb biopsy alone may improve the diagnosis of celiac disease, it remains very important for providers to sample both the duode- 
nal bulb and distal duodenum when entertaining the diagnosis of celiac disease. The varying degree of histology combined with a heterogeneous or patchy distribution within the small bowel necessitates a sampling strategy that includes the duodenal bulb $[10,20]$. The rationale as to why some patients may have villous atrophy exclusively in either the bulb or distal duodenum remains unknown; however, it is plausible to assume this may simply reflect the patchy distribution of the celiac disease-associated lesions [17,27,46,47]. Another explanation may be that ingestion of gluten may cause localized tissue damage in the bulb as this portion of the intestine is rich in lymphatic structures; it is also the initial duodenal site to be exposed to gluten before it is digested [48].

Traditionally, the diagnosis of celiac disease has relied upon multiple endoscopic biopsies collected from the more distal segments of the duodenum. This has been in large part due to concern regarding presence of Brunner glands in the proximal duodenum and fear of interference with evaluation of the villous to crypt ratio $[17,49-51]$. However, in addition to an improved diagnostic accuracy, duodenal bulb sampling resulted in an increase in diagnostic yield of non-celiac etiologies. The most prominent of these diagnoses were Brunner gland hyperplasia and peptic duodenitis (i. e., increased yield of $4 \%$ and $1 \%$, respectively). Therefore, the opportunity to improve the diagnostic efficacy of celiac disease and establish further non-celiac diagnoses is further validation that biopsy of the duodenal bulb is a useful strategy to evaluate select patients.

Limitations of the current study include the inherent heterogeneity bias of pooled systematic reviews and meta-analyses. This current study relies heavily upon observational studies, with no included randomized trials. While publication bias was not formally assessed, sensitivity analysis was performed through inclusion of prospective studies only. Although these studies may be superior to retrospective studies, we cannot discount the overall quality of evidence is less than ideal and may have an effect on the findings of the review. Furthermore, analysis unit problems, inclusion of correlated observations, are not uncommon in clinical research and present a challenge to the reliability of the findings. Other limitations of our study include the inability to define specific patient and biopsy characteristics to further guide practice habits. In accordance with current American College of Gastroenterology guidelines, both serology and biopsy should be performed on patients who consume a gluten-containing diet [7]. Included studies in this systematic review and meta-analysis do not specifically separate patient populations by those adherent or nonadherent to a glutenfree diet. This information would be useful in providing insight as to whether bulb biopsy would be influenced by gluten-free adherence. Pathologic diagnosis of the included studies was as defined by the modified Marsh-Oberhuber classification and did not utilize the more recent, simplified Corazza classification $[9,41,52]$. Furthermore, histology of patients with celiac disease is different in adults as compared to pediatric patients with a higher occurrence of villous atrophy in pediatric populations and milder histologic changes in adults. While this limitation is addressed in our subgroup analysis, biopsy-associated factors were also important limitations. Based upon the study data, we were unable to determine size, number, quality, and orientation of biopsies for all included studies-all of which may affect the histological analysis and influence the identification of celiac disease. This is an important and clinically relevant question to clinicians that requires further study.

Despite these limitations, our study has several strengths. Most importantly, our meta-analysis methodologically summarizes all available data to evaluate the efficacy of duodenal bulb biopsy for the diagnosis of celiac disease. Importantly, our results and confirmation of celiac disease on histology were determined based upon a reproducible and reliable grading system (i.e., the modified Marsh-Oberhuber classification). In addition, the inclusion of both pediatric and adult patients provides a comprehensive answer to the scope of the diagnostic dilemma and easily translates to a wide and diverse practice setting, suggesting that updated guidelines may specifically address this question in both populations. Furthermore, to these authors' knowledge, this is the first study to demonstrate a more beneficial role for duodenal bulb biopsy for adults as compared to children. These results also reaffirm current ACG guidelines for diagnosis of celiac disease and suggest that there is no improvement in diagnostic yield for more than two biopsies from the duodenal bulb. Importantly, our results are in accordance with previous studies demonstrating small-bowel biopsy is also useful for differential diagnosis of other malabsorptive disorders [53]. In our study, duodenal bulb biopsy not only increased the diagnostic yield of celiac disease, but also improved the diagnosis of alternative non-celiac associated gastrointestinal disorders.

\section{Conclusion}

In conclusion, endoscopic sampling of the duodenal bulb in addition to the distal duodenum is recommended to improve histologic diagnosis of celiac disease. While previous studies and results have suggested that patients with high suspicion of celiac disease and positive serum antibodies may not require biopsy sampling in both the bulb or distal duodenum to identify celiac disease-associated lesions, the $5 \%$ increase in diagnostic yield suggests that both biopsy sites are important to confirm the diagnosis. Ultimately, biopsy and histologic examination of duodenal bulb during routine upper endoscopy in evaluation of patients with suspected gluten-sensitive enteropathy appears to increases the diagnostic yield of celiac disease.

\section{Competing interests}

\section{None}




\section{References}

[1] Green PH, Cellier C. Celiac disease. N Engl ] Med 2007; 357: 1731 1743

[2] Gujral N, Freeman H], Thomson AB. Celiac disease: prevalence, diagnosis, pathogenesis and treatment. World J Gastroenterol 2012; 18: $6036-6059$

[3] Fasano A, Berti I, Gerarduzzi T et al. Prevalence of celiac disease in atrisk and not-at-risk groups in the United States: a large multicenter study. Arch Intern Med 2003; 163: 286 - 292

[4] Biagi F, Klersy C, Balduzzi D et al. Are we not over-estimating the prevalence of coeliac disease in the general population? Ann Med 2010; 42: $557-561$

[5] Murray JA, Watson T, Clearman B et al. Effect of a gluten-free diet on gastrointestinal symptoms in celiac disease. Am J Clin Nutr 2004; 79 : $669-673$

[6] Sharaiha RZ, Lebwohl B, Reimers L et al. Increasing incidence of enteropathy-associated T-cell lymphoma in the United States, 19732008. Cancer 2012; 118: 3786-3792

[7] Rubio-Tapia A, Hill ID, Kelly CP et al. ACG clinical guidelines: diagnosis and management of celiac disease. Am J Gastroenterol 2013; 108: $656-676$; quiz 77

[8] Cummins AG, Alexander BG, Chung A et al. Morphometric evaluation of duodenal biopsies in celiac disease. Am J Gastroenterol 2011; 106: $145-150$

[9] Oberhuber G, Granditsch G, Vogelsang H. The histopathology of coeliac disease: time for a standardized report scheme for pathologists. Eur J Gastroenterol Hepatol 1999; 11: 1185-1194

[10] Gonzalez S, Gupta A, Cheng J et al. Prospective study of the role of duodenal bulb biopsies in the diagnosis of celiac disease. Gastrointest Endosc 2010; 72: $758-765$

[11] Mangiavillano B, Masci E, Parma B et al. Bulb biopsies for the diagnosis of celiac disease in pediatric patients. Gastrointest Endosc 2010; 72: $564-568$

[12] Nenna R, Pontone S, Pontone P et al. Duodenal bulb in celiac adults: the "whether biopsying" dilemma. J Clin Gastroenterol 2012; 46: $302-307$

[13] Beynon R, Leeflang MM, McDonald S et al. Search strategies to identify diagnostic accuracy studies in MEDLINE and EMBASE. Cochrane Database Syst Rev 2013: doi:10.1002/14651858.MR000022.pub3

[14] Liberati A, Altman DG, Tetzlaff ] et al. The PRISMA statement for reporting systematic reviews and meta-analyses of studies that evaluate health care interventions: explanation and elaboration. Ann Int Med 2009; 151: W65-W94

[15] Howaizi M, Chahine M, Haydar F et al. Cannabis-induced recurrent acute pancreatitis. Acta Gastroenterol Belg 2012; 75: 446 - 447

[16] Lorvellec A, Thiriet L, Andrianjafy C et al. [Recurrent cannabis-induced acute pancreatitis]. Presse Med 2015; 44: 468-471

[17] Caruso R, Marafini I, Del Vecchio Blanco G et al. Sampling of proximal and distal duodenal biopsies in the diagnosis and monitoring of celiac disease. Dig Liver Dis 2014; 46: 323 - 329

[18] Mansfield-Smith S, Savalagi V, Rao N et al. Duodenal bulb histological analysis should be standard of care when evaluating celiac disease in children. Pediatr Dev Pathol 2014; 17: 339-343

[19] Levinson-Castiel R, Hartman C, Morgenstern S et al. The role of duodenal bulb biopsy in the diagnosis of celiac disease in children. J Clin Gastroenterol 2011; 45: 26-29

[20] Kurien M, Evans KE, Hopper AD et al. Duodenal bulb biopsies for diagnosing adult celiac disease: is there an optimal biopsy site? Gastrointest Endosc 2012; 75: 1190 - 1196
[21] Tanpowpong P, Broder-Fingert S, Katz AJ et al. Predictors of duodena bulb biopsy performance in the evaluation of coeliac disease in children. J Clin Pathol 2012; 65: 791 - 794

[22] Sharma A, Mews C, Jevon G et al. Duodenal bulb biopsy in children for the diagnosis of coeliac disease: experience from Perth, Australia. J Paediatr Child Health 2013; 49: 210 - 214

[23] Evans KE, Aziz I, Cross SS et al. A prospective study of duodenal bulb biopsy in newly diagnosed and established adult celiac disease. Am J Gastroenterol 2011; 106: 1837 - 1842

[24] Bonamico M, Thanasi E, Mariani P et al. Duodenal bulb biopsies in celiac disease: a multicenter study. J Pediatr Gastroenterol Nutr 2008; 47: $618-622$

[25] Rashid M, MacDonald A. Importance of duodenal bulb biopsies in children for diagnosis of celiac disease in clinical practice. BMC Gastroenterol 2009; 9: 78

[26] Prasad KK, Thapa BR, Nain CK et al. Assessment of the diagnostic value of duodenal bulb histology in patients with celiac disease, using multiple biopsy sites. J Clin Gastroenterol 2009; 43: 307 - 311

[27] Bonamico M, Mariani P, Thanasi E et al. Patchy villous atrophy of the duodenum in childhood celiac disease. J Pediatr Gastroenterol Nutr 2004; 38: $204-207$

[28] Ravelli A, Bolognini S, Gambarotti M et al. Variability of histologic lesions in relation to biopsy site in gluten-sensitive enteropathy. Am J Gastroenterol 2005; 100: 177-185

[29] Stoven SA, Choung RS, Rubio-Tapia A et al. Analysis of biopsies from duodenal bulbs of all endoscopy patients increases detection of abnormalities but has a minimal effect on diagnosis of celiac disease. Clin Gastroenterol Hepatol 2016; 14: 1582 - 1588

[30] Mooney PD, Kurien M, Evans KE et al. Clinical and immunologic features of ultra-short celiac disease. Gastroenterology 2016; 150 $1125-1134$

[31] Lebwohl B, Sanders DS, Green PHR. Coeliac disease. Lancet 2018; 391 : $70-81$

[32] Malekzadeh R, Sachdev A, Fahid Ali A. Coeliac disease in developing countries: Middle East, India and North Africa. Best Pract Res Clin Gastroenterol 2005; 19: 351 - 358

[33] Rubio-Tapia A, Ludvigsson JF, Brantner TL et al. The prevalence of celiac disease in the United States. Am J Gastroenterol 2012; 107 : $1538-1544$; quiz 7, 45

[34] Catassi C, Fabiani E, Ratsch IM et al. The coeliac iceberg in Italy. A multicentre antigliadin antibodies screening for coeliac disease in school-age subjects. Acta Paediatr Suppl 1996; 412: 29 - 35

[35] Bai JC, Ciacci C. World Gastroenterology Organisation Global Guidelines: Celiac Disease February 2017. J Clin Gastroenterol 2017; 51 $755-768$

[36] Hill ID, Fasano A, Guandalini S et al. NASPGHAN Clinical report on the diagnosis and treatment of gluten-related disorders. J Pediatr Gastroenterol Nutr 2016; 63: 156-165

[37] Force USPST, Bibbins-Domingo K, Grossman DC et al. Screening for Celiac Disease: US Preventive Services Task Force Recommendation Statement. JAMA 2017; 317: 1252 - 1257

[38] Downey L, Houten R, Murch S et al. Recognition, assessment, and management of coeliac disease: summary of updated NICE guidance. BMJ 2015; 351: h4513

[39] Rubin CE, Brandborg LL, Phelps PC et al. Studies of celiac disease. I. The apparent identical and specific nature of the duodenal and proximal jejunal lesion in celiac disease and idiopathic sprue. Gastroenterology 1960; 38: $28-49$

[40] Fry L, Seah PP, McMinn RM et al. Lymphocytic infiltration of epithelium in diagnosis of gluten-sensitive enteropathy. Br Med J 1972; 3: $371-374$ 
[41] Marsh MN. Gluten, major histocompatibility complex, and the small intestine. A molecular and immunobiologic approach to the spectrum of gluten sensitivity ('celiac sprue'). Gastroenterology 1992; 102: $330-354$

[42] Marsh MN, Crowe PT. Morphology of the mucosal lesion in gluten sensitivity. Baillieres Clin Gastroenterol 1995; 9: 273-293

[43] Ferguson A, Arranz E, O'Mahony S. Clinical and pathological spectrum of coeliac disease - active, silent, latent, potential. Gut 1993; 34: $150-151$

[44] Troncone R, Greco L, Mayer M et al. Latent and potential coeliac disease. Acta Paediatr Suppl 1996; 412: 10-14

[45] Shiner M. Small intestinal biopsy: diagnostic and research value. Proc R Soc Med 1959; 52: $10-14$

[46] Hopper AD, Cross SS, Sanders DS. Patchy villous atrophy in adult patients with suspected gluten-sensitive enteropathy: is a multiple duodenal biopsy strategy appropriate? Endoscopy 2008; 40: 219 224

[47] Vogelsang $\mathrm{H}$, Hanel S, Steiner B et al. Diagnostic duodenal bulb biopsy in celiac disease. Endoscopy 2001; 33: $336-340$
[48] Ravelli A, Villanacci V. Tricks of the trade: How to avoid histological pitfalls in celiac disease. Pathol Res Pract 2012; 208: 197- 202

[49] Institute AGA. AGA Institute Medical Position Statement on the Diagnosis and Management of Celiac Disease. Gastroenterology 2006; 131: $1977-1980$

[50] Hill ID, Dirks MH, Liptak GS et al. Guideline for the diagnosis and treatment of celiac disease in children: recommendations of the North American Society for Pediatric Gastroenterology, Hepatology and Nutrition. J Pediatr Gastroenterol Nutr 2005; 40: 1 - 19

[51] Trier JS. Diagnostic value of peroral biopsy of the proximal small intestine. N Engl J Med 1971; 285: 1470 - 1473

[52] Corazza GR, Villanacci V, Zambelli C et al. Comparison of the interobserver reproducibility with different histologic criteria used in celiac disease. Clin Gastroenterol Hepatol 2007; 5: 838-843

[53] Yantiss RK, Odze RD. Optimal approach to obtaining mucosal biopsies for assessment of inflammatory disorders of the gastrointestinal tract. Am J Gastroenterol 2009; 104: 774-783 


\section{Study}

\begin{tabular}{l} 
Caruso et al. (2013) \\
Mansfield-Smith et al. (2014) \\
Overall $\left(I^{2}=0.0 \%, P=0.00\right)$ \\
\hline Proportion \\
.1 .2 .3 .4 .5 .6 .7 .8 .91
\end{tabular}

- Supplemental Fig. 1 Diagnostic yield increase of duodenal bulb biopsy versus distal duodenal biopsy for the diagnosis of Brunner

\section{Study}

\begin{tabular}{l} 
Caruso et al. (2013) \\
Mansfield-Smith et al. (2014) \\
Overall $\left(I^{2}=0.0 \%, P=0.00\right)$ \\
\hline $\begin{array}{c}1 \\
\text { Proportion }\end{array}$
\end{tabular}

- Supplemental Fig. 2 Diagnostic yield increase of duodenal bulb biopsy versus distal duodenal biopsy for the diagnosis of peptic

\section{Study}

Bonamico et al. (2004)

Ravelli et al. (2005)

Bonamico et al. (2008)

Prasad et al. (2009)

Rashid et al. (2009)

Gonzalez et al. (2010)

Mangiavillano et al. (2010)

Evans et al. (2011)

Levinson-Castiel et al. (2011)

Kurien et al. (2012)

Nenna et al. (2012)

Caruso et al. (2013)

Mooney et al. (2016)

Stoven et al. (2016)

Overall $\left(I^{2}=79.06 \%, P=0.00\right)$

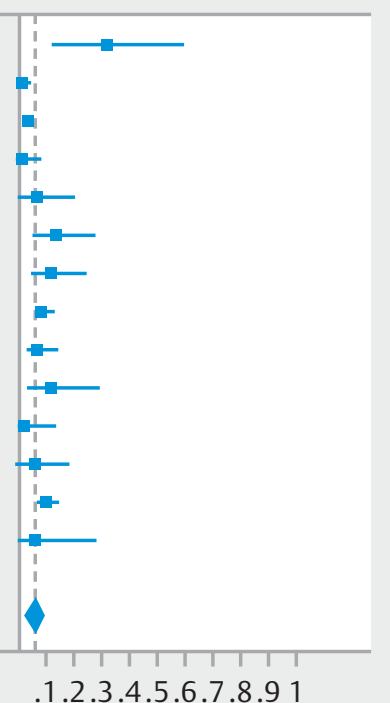

Proportion

Supplemental Fig. 3 Overall diagnostic yield increase of duodenal bulb biopsy versus distal duodenal biopsy for the diagnosis of celiac disease - prospective, high-quality studies only.

\section{Study}

Bonamico et al. (2004)

Ravelli et al. (2005)

Bonamico et al. (2008)

Prasad et al. (2009)

Rashid et al. (2009)

Levinson-Castiel et al. (2011)

Tanpowpong et al. (2012)

Sharma et al. (2013)

Mansfield-Smith et al. (2014)

Mangiavillano et al. (.)

Overall $\left(I^{2}=85.31 \%, P=0.00\right)$

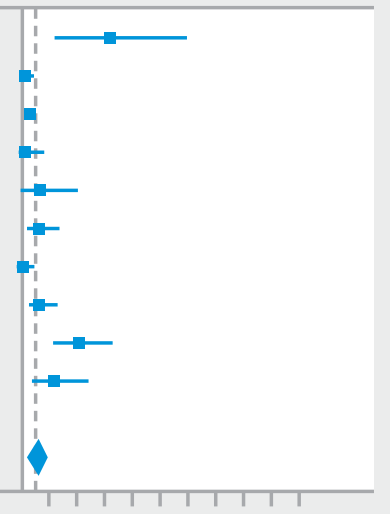

1.2.3.4.5.6.7.8.9 1

Proportion

- Supplemental Fig. 4 Diagnostic yield increase of duodenal bulb biopsy versus distal duodenal biopsy for the diagnosis of celiac

\section{Study}

Gonzalez et al. (2010)

Evans et al. (2011)

Kurien et al. (2012)

Nenna et al. (2012)

Caruso et al. (2013)

Mooney et al. (2016)

Stoven et al. (2016)

Overall $\left(I^{2}=0.00 \%, P=0.60\right)$

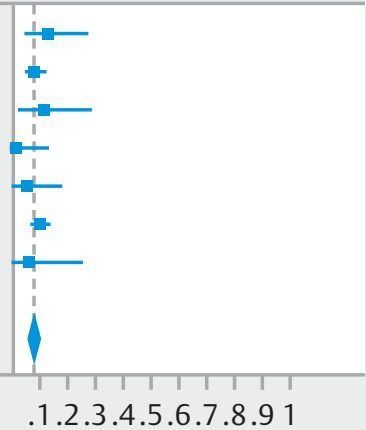

Proportion

- Supplemental Fig. 5 Diagnostic yield increase of duodenal bulb biopsy versus distal duodenal biopsy for the diagnosis of celiac disease among adult patients. 


\section{Study}

Bonamico et al. (2004)

Ravelli et al. (2005)

Bonamico et al. (2008)

Rashid et al. (2009)

Gonzalez et al. (2010)

Mangiavillano et al. (2010)

Evans et al. (2011)

Levinson-Castiel et al. (2011)

Kurien et al. (2012)

Tanpowpong et al. (2012)

Caruso et al. (2013)

Sharma et al. (2013)

Mansfield-Smith et al. (2014)

Mooney et al. (2016)

Stoven et al. (2016)

Overall $\left(I^{2}=83.43 \%, P=0.00\right)$

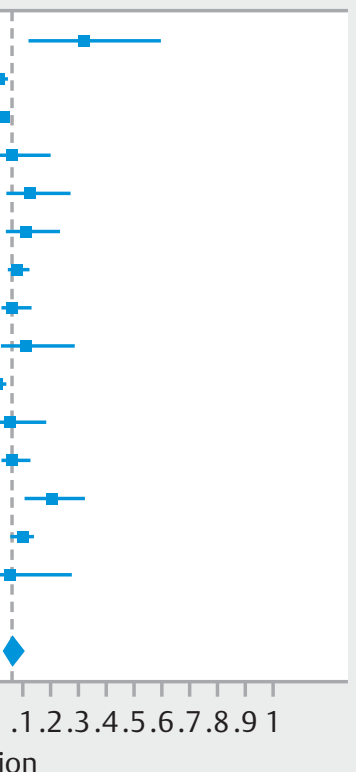

Proportion

- Supplemental Fig. 6 Overall diagnostic yield increase of duodenal bulb biopsy versus distal duodenal biopsy for the diagnosis of celiac disease among studies following American College of Gastroenterology guidelines. 